\title{
Arte, documento y fotografía: prolegómenos para una reformulación del campo fotográfico en Chile (1977-1998) ${ }^{1}$
}

\author{
Art, Document and Photography: Prolegomena \\ for a reformulation of the Photography Field \\ in Chile (1977-1998)
}

\author{
Ángeles Donoso Macaya \\ SUNY New Paltz, Estados Unidos \\ donosoa@newpaltz.edu
}

- Resumen - Este artículo aborda los espacios discursivos de la fotografía en Chile en el período de la Dictadura y la Transición. A partir de algunos planteamientos de Régis Durand, Rosalind Krauss y Jacques Rancière, se sugiere la necesidad de redefinir «lo fotográfico» para, primero, poder repensar la división que se da en las prácticas fotográficas del período en relación a los usos y valores asignados a la fotografía «documental» y la fotografía «creativa»y, segundo, reflexionar sobre la irrupción del aparato fotográfico dentro del territorio de las artes visuales y de la crítica.

Palabras clave: fotografía documental y experimentalismo, campo fotográfico, memoria y representación visual, Mario Fonseca, Asociación de Fotógrafos Independientes.

Abstract . This article explores the discursive spaces of photography in Chile from the mid seventies until the mid nineties. Departing from notions developed by Régis Durand, Rosalind Krauss, and Jacques Rancière, it argues that it is necessary to redefine «the photographic» in order to, first, be able to rethink the divisions, uses, and values assigned to both «documentary» photography and «creative» photography, and second, reflect upon the irruption of the photographic apparatus into the spaces of the visual arts and of academic criticism from this period.

Keywords: Documentary Photography and Experimentalism, Photographic Field, Memory and Visual Representation, Mario Fonseca, AFI.

El siguiente artículo forma parte de una investigación en curso financiada por el FONDART 2012 en el área Investigación y Actividades Formativas (Folio 13991), titulada «Memoria fotográfica: estéticas y políticas de la representación en Chile, 1980-1990». 
Hay que saber mirar en las imágenes aquello de lo que ellas son sobrevivientes. Para que así la historia, liberada del puro pasado (ese absoluto, esa abstracción) nos ayude a abrir el presente del tiempo.

Didi-Huberman, Images Malgré Tout ${ }^{2}$.

La apertura de un espacio de exhibición dedicado exclusivamente a la fotografía es uno de aquellos hitos que consolidan su estatus dentro de un campo cultural determinado. En este sentido, la inauguración de la Galería AFA, en el año 2006, marca un hito en el campo de la fotografía en Chile. La fotógrafa Andrea Jösch, curadora de AFA 01 (la primera muestra realizada en la galería), celebra en su texto de presentación aquellas iniciativas (gestión de espacios, ventas, muestras, coleccionismo, crítica, etc.) que "han ido configurando nuestra no historia de la fotografía chilena» (34) y evoca los hitos de lo que ella denomina la «transición fotográfica [de] los últimos 18 años» (34), estableciendo una correlación entre la historia política del país y la historia de la fotografía. Entre estas iniciativas, Jösch destaca el Día Nacional de la Fotografía como «el punto preciso de este tan anhelado término de transición: el hecho de reconocer públicamente, luego de 17 años de espera, a nuestros antecesores de la cámara» (36). Sin lugar a dudas, desde mediados de los años noventa el campo de la fotografía se ha visto energizado y revalidado por iniciativas como las descritas por Jösch: festivales, bienales y congresos internacionales, homenajes, muestras, apertura de espacios y galerías. Cabe mencionar todavía otra veta (de carácter más meta o autoreflexivo) de esta primavera fotográfica: en la última década, fotógrafos, artistas, especialistas y académicos, así como diversas instituciones privadas y organismos públicos, se han dedicado a fomentar la investigación, conservación y difusión de la fotografía en Chile, a través de la publicación de catálogos, antologías, libros de autor y estudios. En definitiva, tal como sugiere Jösch, ha sido posible atestiguar en el nuevo milenio el interés cada vez más creciente por parte de fotógrafos, académicos y críticos en reconstruir -o mejor dicho, construir- la historia del campo de la fotografía y de la producción fotográfica nacional desde sus orígenes ${ }^{3}$.

2 Dice el original en francés: «Il faudrait savoir regarder dans les images ce dont elles sont les survivantes. Pour que l'histoire, libérée du pur passé (cet absolu, cette abstraction), nous aide à ouvrir le présent du temps» (226, el énfasis es original).

3 Ver, por ejemplo, Fotógrafos en Chile durante el siglo XIX (2001) y el recientemente aparecido Fotógrafos en Chile 1900-1950 (2012), ambos de Hernán Rodríguez Villegas y editados por el Centro Nacional del Patrimonio Fotográfico. Sobre el período que me atañe directamente (desde fines de los setenta hasta mediados de los noventa), se han publicado varios libros de fotografía, entre ellos Fragmento fotográfico y Marcas crónicas, de Kena Lorenzini; Irredimible de Marcelo (y Christián) Montecino; Álvaro Hoppe: el ojo en la historia y Luis Navarro: la potencia de la memoria, ambos a cargo de Gonzalo Leiva Quijada; además de los estudios AFI: Multitudes en sombra y «Fotografía y conflicto en el campo expandido de la estética dictatorial chilena (19811989)» (del mismo Leiva), ¿Quién es el autor de esto? Fotografía y performance y Yo, Fotografía de Rita Ferrer; Fotografía o la cotidiana finta de la experiencia, editado por José Pablo Concha; y el número especial de Aisthesis dedicado a la fotografía en 2005. La sección sobre fotografía de www. memoriachilena.cl también ha jugado un importante rol, así como el Área de Fotografía del CNCA, creada en el 2005. 
En contraste al prometedor panorama que se delinea en intervenciones como la de Jösch -así como en tantos otros catálogos, libros, revistas y presentaciones de fotografía en esta última década-, los años setenta y ochenta parecen marcados por una ambivalencia discursiva que se mueve entre dos extremos: por un lado, voces que celebran el relativo renacer o despertar de la actividad fotográfica a inicios de los ochenta; por otro, discursos que dan cuenta de una sentida precariedad en la que se habría desarrollado la fotografía en Chile durante todo ese periodo ${ }^{4}$. Este afecto de precariedad se hace manifiesto, por ejemplo, en el conocido texto que acompañara la selección fotográfica de la exposición Chile Vive, realizada en Madrid en 1987. En las primeras líneas, Mario Fonseca anuncia, tajante: «No hay historia, no hay crítica, no hay mercado. Hacer la fotografía en Chile es hoy una aventura, como también lo es escribir este texto» («A propósito de la fotografía» 33) . Paradójicamente, un estudio detenido de los discursos y prácticas de la época revela un campo de una complejidad y riqueza extremas que difiere bastante del paisaje que pintara Fonseca en su texto. El sentimiento de que asistimos al despertar, o reemergencia de la fotografía, se hace palpable en el tono de urgencia de muchos de estos discursos. Así, por ejemplo, en el Primer Anuario Fotográfico Chileno, publicado en 1981 por la Agrupación Cultural Puliwen-Antu, los editores anuncian:

Hemos visto, a partir de 1980, un despertar en el quehacer fotográfico de nuestro país. Se han dado a conocer nuevos nombres y nuevas búsquedas. Nos parece que esta generación, la generación del 70, se muestra fortalecida, equilibrada [...] En este momento resulta ineludible canalizar un movimiento que ya es visible. Debemos hacerlo palpable $(\mathrm{s} / \mathrm{p})$.

Ideas como las manifestadas en este Primer Anuario no invalidan la aseveración de Fonseca, al contrario: la tensión y la urgencia presentes en los distintos discursos son los que nos invita a estudiar el aparato sobre el que se sostiene aquella sentida precariedad, la cual se percibe, sobre todo, en el discurso de los mismos fotógrafos.

El siguiente estudio tiene como objetivo, entonces, indagar críticamente en los espacios discursivos de la fotografía en el período que va desde mediados de los años setenta hasta mediados de los años noventa. Con espacios discursivos me refiero a los espacios de difusión, debate y crítica, así como a las prácticas y los discursos de fotógrafos, artistas visuales y críticos. Este período resulta particularmente significativo por varias razones. En primer lugar, a fines de los años setenta irrumpe con mucha fuerza el experimentalismo en las artes visuales, y el documento fotográfico adquiere una relevancia sin precedentes en las prácticas de artistas visuales y en el

4 Digo «sentida» en cuanto la precariedad da más cuenta de una «estructura de sentimiento» derivada de ciertas posiciones teóricas conscientes e inconscientes que de una real precariedad del campo en cuanto a circulación y producción.

5 Vale la pena mencionar que, con motivo de AFA01, Fonseca ofrece una revisión de su ensayo de 1986 a la luz del panorama actual. El ensayo se titula, notoriamente, "Chile (sobre) vive: Fotografía en Chile 1986-2006» y aparece publicado en el catálogo de la exposición. 
discurso de críticos de arte y académicos ${ }^{6}$. Dos referencias casi obligatorias en este contexto son Márgenes e instituciones: arte en Chile desde 1973 (1986), de Nelly Richard, y Del espacio de acá: señales para una mirada americana (1980), de Ronald Kay. Como se verá, perspectivas como las de Richard o Kay piensan la fotografía casi exclusivamente a partir de su relación con el arte, más específicamente, a partir de «la introducción del referente fotográfico en el arte chileno» (Richard, Márgenes $44)^{7}$. De hecho, Richard destaca los trabajos «más reflexivos» -en especial los de Eugenio Dittborn- en tanto «se preocuparon especialmente de deconstruir [el] mito de objetividad fotográfica basado en la ilusión referencial de una transparencia del sentido que naturaliza el mensaje» (Márgenes 44). En segundo lugar, la fotografía documental se profesionaliza y se institucionaliza a través de la fundación de la Asociación de Fotógrafos Independientes (AFI) en 1981; este grupo de fotógrafos, además de su trabajo en distintos medios de prensa, gestiona una serie de iniciativas (exposiciones colectivas, talleres, cooperativas) y funda la revista Punto de Vista, que se convierte en el primer canal de difusión de eventos, debates y estudios en torno al campo fotográfico, editado por fotógrafos profesionales. En tercer lugar, la aparición de revistas tales como Apsi, Hoy, Análisis y CAL, desde fines de los años setenta, y luego Cauce, La Bicicleta y el diario La Época (para nombrar solo algunas publicaciones), las cuales, si bien abordan temáticas distintas, ponen en circulación las fotografías «no oficiales» tomadas por muchos de estos fotógrafos, evidenciando, además, el tremendo potencial político de la imagen mediática ${ }^{8}$. Así, en medio de una contingencia histórica que provoca distintas posturas, respuestas y teorizaciones, surgen diversas voces que piensan los espacios y los límites del arte y la fotografía, y su relación con la política, la sociedad y la cultura.

Como se trata de un periodo que recorre gran parte de la Dictadura y el periodo de la Transición, he organizado mi investigación en torno a tres momentos, que corresponden a un conjunto de hechos o hitos que infieren en el campo fotográfico. El primer momento (1976-1977) coincide con la aparición de las revistas Apsi (1976), Hoy y Análisis (1977), y con las exposiciones Nueve relaciones inscritas en el paisaje urbano (1977) de Carlos Altamirano y Fotografía: Sn. Diego esq. Tarapacá, vista: norte-sur, 23 agosto 1977, 12.30 hrs. (1977) de Francisco Smythe. El segundo momento

$6 \quad$ Por ejemplo, en el editorial número 4 de 1979 de la revista CAL, se lee: «Publicamos la traducción de parte del ensayo de Susan Sontag On Photography introducido por Adriana Valdés, como estímulo al necesario desarrollo de una reflexión acerca de la fotografía, cuyo uso es hoy generalizado en el arte chileno; dedicamos también espacio a la reproducción de trabajos de fotógrafos chilenos (Villaseca en el número anterior, Paz Errázuriz en el actual) como contribución a la difusión de la expresión fotográfica» (2).

7 En Márgenes e instituciones, Richard argumenta que la preocupación por el medio fotográfico, demostrada tanto en las obras como en la discusión crítica de la «avanzada», «desplaza» y «reemplaza» a la preocupación que antes manifestaba el grabado (41).

8 Esto se hace patente luego del Bando 19 del Ministerio de Defensa de Chile, el cual aparece en 1984 y consiste en la prohibición de la inclusión de imágenes en revistas y periódicos de oposición (APSI, Análisis, Cauce, Fortín Mapocho). Esto impulsó a revistas como Cauce a responder de manera creativa y crítica. Una lectura clave al abordar este tema es la respuesta de Enrique Lihn publicada en sus Notas de arte, "Sobre la fotografía: el reportaje gráfico y las fotos censuradas». 
corresponde a un período más extenso (desde 1981 a 1988), el cual se inicia con la fundación de la Asociación de Fotógrafos Independientes (AFI) y la inauguración de la revista Punto de Vista en 1981, e incluye varias iniciativas y exposiciones colectivas, entre ellas, Calle San Diego (1982), Acá y allá, Ahora Chile y Artes e industrias de la sobrevivencia (realizadas en 1983), Colectivo AFI (1984), 13 fotógrafos (1986), Somos +, Colectivo AFI y Chile Vive (realizadas en 1987), las publicaciones de dos anuarios (el Primer Anuario de Fotografía Chilena en 1981 y el Segundo Anuario de Fotografía Chilena en 1982) y Ediciones económicas de la fotografía chilena (1983). El tercer momento (1996-1998), corresponde a tres exposiciones realizadas en el Museo de Bellas Artes: en 1996, Los límites de la fotografía, curada por André Rouillé y la retrospectiva de Mario Fonseca, Fotografías c. 1986-1995, y en 1998, Fotografía: Intervenciones, Cruces y Desvíos, curada por Enrique Zamudio.

Estos tres momentos, entonces, se componen de una serie de hitos o hechos que van a conformar la base de las plataformas discursivas de esta investigación. En una primera etapa, la tarea ha sido trazar, desde la teoría, ciertos lineamientos que me permitan replantear, por un lado, la división que se da en las mismas prácticas fotográficas del período en relación a los usos y valores asignados a la fotografía documental y la fotografía artística, y, por otro, la irrupción del documento fotográfico y del aparato fotográfico dentro del territorio de las artes visuales y de la crítica. Es decir, cuestiones que tienen que ver con la autonomización de la fotografía (Durand 15), la cual -y aquí agregamos algo al modelo de Durand- se refiere no solo a la autonomía de la fotografía llamada «creativa» o "puramente artística» en relación a sus «funciones tradicionales (reportaje, documentación, publicidad, etc.)» (15), sino que también al desplazamiento del valor de documento del reportaje gráfico y su revaloración (añadida) como objeto estético, lo que se aprecia en el caso de fotógrafos como Álvaro Hoppe, Kena Lorenzini, Paz Errázuriz o Marcelo Montecino, entre otros. En definitiva, más que de un problema relativo a los «límites» del campo artístico y de la fotografía en función al campo del arte, mi planteamiento es que se trata de un problema del campo de la fotografía y de los límites y desplazamientos de la noción de lo documental en este campo.

Para analizar el campo de la fotografía en el Chile de la Dictadura y la Transición, entonces, se vuelve fundamental examinar el fenómeno de lo fotográfico y su lenguaje específico. Con «lo fotográfico» me refiero tanto al conjunto de prácticas fotográficas como a los discursos sobre éstas, a las oposiciones entre fotografía artística y documental, a los desplazamientos del documento fotográfico en el campo del arte y a las teorizaciones que a partir de la fotografía se dan de la imagen mediática. El fenómeno de lo fotográfico circunda y pone en relación todas estas cuestiones. En palabras de Philippe Dubois, lo fotográfico es una categoría «fundamentalmente epistémica [...] que da paso a una relación específica con los signos, el tiempo, el espacio, lo real, el sujeto, con el ser y el hacer» (54). Esta noción de lo fotográfico no nos reenvía tanto a la (s) fotografía (s) como objeto (s) de estudio, sino que más bien 
abre el campo de los estudios visuales a las relaciones entre medios de comunicación, artes visuales, fotografía «documental» y/o «artística», estética y política, a partir del fenómeno fotográfico y de los espacios discursivos ocupados por la fotografía.

La noción de «lo fotográfico» es pensada como categoría teórica por primera vez en una serie de ensayos escritos por Rosalind Krauss reunidos en Le Photographique: pour un Théorie des Écarts [Lo fotográfico: por una teoría de los desplazamientos]. A partir de lecturas sobre los precursores del medio -Nadar, Talbot-y en diálogo con las ideas planteadas por Walter Benjamin y Roland Barthes, Krauss propone dos ideas fundamentales: primero, que la historia de la fotografía durante el siglo XIX no puede ser elaborada desde los parámetros de la historia del arte (esto es, desde categorías como estilo, autor, obra, etc.), para lo cual se vuelve necesario identificar los espacios discursivos de la fotografía en cada período; segundo, que la fotografía como aparato modifica, a partir de Duchamp y el surrealismo, el campo del arte (sus modos de producción, apreciación y crítica). Esta modificación no pasa por la inclusión de la fotografía como material o herramienta dentro de la obra, sino que por un desplazamiento total de la obra desde el modelo icónico al modelo indicial. A partir de los años sesenta, sugiere Krauss, se da un cambio o una sustitución dentro del campo del arte, de las reglas de la iconicidad por las de indexación (en sus palabras, Duchamp remplaza a Picasso). Este desplazamiento propone una nueva interpretación del signo estético. Para Krauss, entonces, la cuestión no pasa por hablar «sobre fotografía " ${ }^{9}-$ la autora repite en distintas ocasiones que la fotografía no es su objeto de estudio-, sino sobre la naturaleza del índice y sobre las condiciones indiciales en que la fotografía sumió al campo antiguamente cerrado del mundo del arte (14). Para eso, Krauss utiliza lo fotográfico como objeto teórico. Según Krauss, es la especificidad semiológica de la fotografía en tanto "índice» (más que como «ícono») lo que permite transformarla en objeto teórico por medio del cual las obras de arte puedan ser vistas en términos de su función como signo (13).

Si bien el modelo de Krauss puede resultar productivo para pensar en el campo del arte, no resulta suficiente para pensar en el campo de la fotografía. El problema reside, por un lado, en que la postulación de «lo fotográfico» como categoría teórica le sirve a Krauss para hablar exclusivamente sobre el campo del arte; por otro, Krauss destaca o prioriza la naturaleza indicial o indexical del signo fotográfico, dejando de lado su condición de símbolo. El signo fotográfico es, en todo momento, un signo complejo: parte índice, parte ícono y parte símbolo, como sugiere José Pablo Concha (La desmaterialización 37-8); complejidad que se hace manifiesta también en los espacios discursivos de la fotografía. Por eso, si bien tomo como fundamento los

\footnotetext{
«Para [Barthes], la fotografía está constituida por el hecho bruto de su estatus como prueba, testigo mudo sobre el cual 'no hay nada que añadir'. En este preciso instante, cuando lo que le da valor de prueba se esencializa, la fotografía cambia de estatus y se convierte en objeto teórico, es decir en una especie de casillas o de filtro mediante el cual es posible organizar los datos de otro campo que se halla con relación a él en una posición secundaria. La fotografía es el centro desde el cual se puede explorar dicho campo, pero debido a esta posición central, la fotografía se convierte, de algún modo, en una mancha ciega. Nada que decir, o al menos nada sobre la fotografía» (Krauss 14).
} 
planteamientos de Krauss y Dubois sobre lo fotográfico, lo hago sin limitar el signo fotográfico a uno u otro aspecto semiológico, sino que considerándolo como signo complejo. Esta reformulación de lo fotográfico es necesaria al estudiar el campo de la fotografía en el período de la Dictadura y la Transición, ya que permite revisitar y repensar un campo que se delineó a partir de ciertas oposiciones, contradicciones y cruces, las cuales tienen que ver, muchas veces, con distintas formulaciones del signo fotográfico como huella o como artificio, como traza o como símbolo.

Una de las oposiciones que se articula en el campo discursivo de la fotografía en esta época es la oposición entre el modo de hacer documental de la fotografía y el uso «experimental» del documento fotográfico en el campo de las artes visuales; otra oposición, esta vez dentro del mismo campo de la fotografía, es la que se delinea entre la fotografía de registro documental y la fotografía creativa o artística. Ambas oposiciones tienen que ver con un cierto modo de comprensión de «lo documental» y de la cualidad indicial del signo fotográfico. Una consecuencia fundamental de esta formulación es que la fotografía "creativa» y aquella realizada o utilizada dentro del campo de las artes visuales tiende a ser privilegiada, en el discurso crítico-académico, en desmedro de la fotografía documental, entre otras razones, porque la fotografía documental es apreciada casi exclusivamente en relación a su referente (su valor informacional predomina por sobre cualquier otro valor). Como se verá en el Apartado I, la posición marginal de la fotografía documental en relación al campo del arte y en relación al discurso académico sigue imperando hacia fines de los noventa.

Pese a que el debate de si la fotografía es arte o no parece ser «tan viejo como la fotografía misma» (Durand 15), el hecho de que aparezca en distintos momentos y bajo distintas ópticas lleva a Durand a sugerir que es "parte integrante de la historia de la fotografía» (15). Y es que la imagen fotográfica, según Durand, parece estar constantemente «en un estatuto indecidible: ni significante ni insignificante [...] ni índice ni icono [...] Ese carácter indecidible contribuye [...] a la fascinación que ejerce y explica la riqueza de los usos a los que se presta en la creación contemporánea» (15). Examinar el fenómeno de lo fotográfico, entonces, nos permite productivizar esta indecidibilidad de la fotografía, dentro y fuera del ámbito de la creación artística: indecidibilidad presente en la tensión inherente a la imagen fotográfica, la cual se manifestaría en la capacidad que tienen las fotografías de decir o no decir, de producir semblanzas o discrepancias entre lo visto y lo no visto, lo dicho y lo no dicho; indecidibilidad manifiesta también en la oposición entre fotografía artística y fotografía documental, en los desplazamientos del documento fotográfico desde los medios de prensa y el archivo hacia las artes visuales, así como en los debates en torno a la imagen de registro documental en tanto imagen mediática. Esta indecidibilidad se hace patente también, por cierto, en el complejo entramado de discursos que aborda el fenómeno fotográfico a lo largo de este período. 


\section{LA FOTOGRAFÍA ANTE EL MUSEO: PRÁCTICAS Y DISCURSOS}

En el año 1996, se realizan en el Museo Nacional de Bellas Artes dos exposiciones que, en el contexto de esta investigación, resultan paradigmáticas. La primera es la exposición titulada Los limites de la fotografía, curada por André Rouillé, en la cual se exhibieron obras de artistas chilenos, argentinos y franceses. Entre los chilenos se encontraban los artistas visuales Gonzalo Díaz, Alfredo Jaar, Eduardo Vilches, Alicia Villareal y Enrique Zamudio. La curatoría de Rouillé pone el énfasis en artistas visuales que aluden al lenguaje fotográfico desde variadas plataformas (video arte, instalación) o que usan el medio fotográfico para pensar, entre otras cosas, en la artificialidad de la obra y en la relación entre presentación y representación o en las ideologías de la mirada. A pesar de que el título de la exhibición nos invita a pensar en cuestiones relativas al campo de la fotografía o, al menos, en aquellos límites y condiciones que tendrían que ver con el aparato fotográfico, uno puede plantear que no es la fotografía per se, sino el advenimiento de lo fotográfico como material artístico y teórico aquello que el proyecto curatorial de Rouillé intenta destacar. Si bien las obras de los artistas congregados plantean cuestiones del todo relevantes en torno al fenómeno fotográfico y su inferencia en el campo de las artes visuales, en la introducción del catálogo de la exposición Rouillé plantea una separación bastante tajante y simple entre lo que reconoce como fotografía artística o "postfotografía» y fotografía «útil» (emparentada aquí con la tradición documental), la cual queda, en este contexto, fuera del espacio del Museo. Dice Rouillé:

El proceso por el cual la fotografía ha pasado de ser útil a convertirse en un material del arte contemporáneo corresponde a lo que yo he llamado «postfotografía» [...] Este pasaje del útil al material [...] es lo que opera una ruptura decisiva entre la tradición documental y su opuesto: la fotografía artística; es lo que separa a los artistas que son fotógrafos a un tiempo de los fotógrafos-artistas (5).

El catálogo de esta exposición incluye un recuento del panorama chileno a cargo de Nelly Richard. En este recuento histórico-crítico, la autora intenta explicar por qué es la obra de artistas visuales -y no la de fotógrafos- la que se congrega en esta exposición: "A diferencia de lo ocurrido en [el] campo de las artes visuales [Richard está hablando aquí del período de la Dictadura], la falta de vinculaciones entre la red de la fotografía personal y otros circuitos de reflexión crítico-cultural sobre la imagen influyó para que las prácticas de los fotógrafos chilenos tendieran a permanecer alejadas de todo entrecruzamiento de soportes y técnicas» («Bordes, límites» 7). Pero aquellos fotógrafos supuestamente desvinculados de estos «circuitos de reflexión crítico-cultural» que Richard menciona realizan una cantidad considerable de exhibiciones colectivas y eventos en espacios como el Instituto Chileno-Francés, la sala Arturo Edwards del Instituto Chileno Británico, la sala El túnel del Instituto Chileno Norteamericano, el Instituto Goethe, todos espacios de gran circulación, es más, son los puntos neurálgicos de la actividad cultural a lo largo de la década de 
los ochenta y noventa. Es decir, los fotógrafos no estaban tan desconectados como sugiere Richard. Lo anterior refleja una clara división del campo y explica, en parte, el hecho de que se lo describa como precario y hostil, como se verá a continuación.

La segunda exposición es precisamente la retrospectiva del artista visual y fotógrafo Mario Fonseca (Fotografías c. 1986-1995). Fonseca fue uno de los gestores, por así decirlo, de la escena de las artes visuales en la década de los ochenta: organizó exhibiciones, abrió galerías y contribuyó en la publicación de libros y catálogos de varios autores y artistas, entre ellos los de Ronald Kay, Paz Errázuriz, Eugenio Dittborn, Raúl Zurita, el grupo CADA, Lotty Rosenfeld, Gonzalo Díaz y Alfredo Jaar. Sin embargo, como artista visual la posición de Fonseca fue más bien marginal -en una entrevista reciente confiesa que "[sintió] que [le habían dado] el espacio [de la Galería Sur en 1982] por compromiso, por la ayuda que [él] venía dando a la movida en aquella época» («Habeas Corpus»s/p) ${ }^{10}$-. En el catálogo, Justo Pastor Mellado se refiere en extenso a la trayectoria fotográfica de Fonseca. Lo más notable, sin embargo, es un pasaje en el que destaca la continua labor de Fonseca en el campo de la fotografía en Chile a lo largo de los ochenta, reparando,en el mismo pasaje, en que críticos como Richard y Kay:

se plantean como críticos de artes visuales y abordan el campo fotográfico desde plataformas discursivas respecto de las cuales las obras consideradas aparecen como complejos síndromes ilustrativos [...] el objeto no es la fotografía en términos específicos, sino la validación discursiva de las nociones de base puestas en operación por estos autores [...]. Aun así es curioso que en 1987 no sea [ni Richard ni Kay] quien escriba sobre la situación del campo fotográfico chileno. En verdad, Fonseca es el único que en ese momento reivindica la identidad discursiva autónoma para dicho campo, declarando las dificultades conceptuales de esta constitución. Es lamentable que no exista un corpus discursivo que reivindique la obra de Antonio Quintana, Jorge Sauré, Sergio Larraín y muchos otros. No se trata de una constitución gremial,

10 En 1982, Fonseca realiza la exposición Habeas Corpus en la Galería Sur. En una entrevista concedida a la revista online Escáner con motivo de la nueva exposición de Habeas Corpus en la Estación Mapocho, Fonseca comenta: «La muestra original de Habeas Corpus no fue muy feliz para mí, se escribieron textos sin firmar individualmente, casi sentí que me dieron el espacio por compromiso por la ayuda que venía dando a la movida en aquella época (publicación de Del Espacio de Acá expo Dávila en CAL, etc.), pero creo también que la potencia de mi cara tapada con un rectángulo negro y la frase Habeas Corpus debajo, en pleno 1982, le resultó muy 'complicada' a la Escena de Avanzada y Cía. Ltda. Algo así le pasó a Jaar con su muestra de 1979 en CAL y su participación en los concursos de la época, él salió adelante con su carrera fuera de Chile, ya sabemos el resto [...] Lo que me movió a hacer esos trabajos entre 1979 y 1982. En síntesis, hay una doble metáfora que se cruza: el recurso legal del habeas corpus-presentar el cuerpo- utilizado en aquel periodo, aunque con pocos resultados, para exigir la presentación de las personas detenidas por la Dictadura, muchas de las cuales simplemente desaparecían, y la demanda que me hago a mí mismo, conminándome a dar la cara como artista autocensurado y autodesaparecido. A este cruce se sumó una tercera 'metáfora' impensada, que fue la censura y desaparición de mi persona como artista, por parte del poder dictatorial de entonces ejercido por ciertas personas de la escena de avanzada, situación que ha persistido hasta hoy sin ningún viso de reconocimiento de lo obrado ni reparación a tantos artistas de la época, a pesar que ya van 20 años de democracia» (Fonseca, «Habeas Corpus» s/p). Quizás, la retrospectiva de 1996 en el Bellas Artes pueda ser apreciada como un reconocimiento $a$ posteriori a su labor artística. 
sino patrimonial. Hay una imagen de la fotografía chilena que no ha sido ligada (s/p, énfasis en el original).

Mellado se refiere aquí al texto que Fonseca escribiera como curador de la selección de fotografías que formó parte de Chile Vive, citado en la introducción de este artículo.

Al considerar Los limites de la fotografía y la retrospectiva de Fonseca en conjunto, resulta notable la existencia de, al menos, dos tipos de discursividad en pugna en torno a lo que se entiende o se percibe como «fotografía» en Chile. El balance de Mellado apunta a la manera en que la fotografía es teorizada desde el campo de las artes visuales en ese período. En gran parte de estos discursos se cruzan, por un lado, la oposición entre fotografía artística y fotografía documental, y, por otro, debates sobre la pertenencia de la fotografía dentro del campo de las artes visuales y sobre la autonomía discursiva de la fotografía como lenguaje y como práctica. Rita Ferrer destaca en este sentido el impacto que genera el fenómeno fotográfico en los discursos que emergen al interior del campo de las artes visuales ya en los años setenta:

La reproducción mecánica de la imagen fotográfica y su consecuente valorización como imagen precaria fueron detonantes para la producción de ciertos discursos sobre lo fotográfico a fines de los años setenta en Chile. La reflexión en torno a la fotografía alteró de un modo determinante el devenir, hasta ese momento más o menos tranquilo, de las prácticas artísticas cuya estratificación de los géneros solo llegaba al grabado numerado (25).

El complejo entramado de discursos que emerge hacia fines de esta década se compone de voces que provienen de áreas diversas: teóricos y críticos de las artes visuales como los ya mencionados Richard, Kay y Mellado; escritores como Enrique Lihn, académicos como Adriana Valdés o Claudia Donoso; fotógrafos como Fonseca, Paz Errázuriz, Álvaro Hoppe, Claudio Pérez y Kena Lorenzini; periodistas y aficionados. Estos discursos proponen ideas divergentes sobre lo que se entiende o se percibe como "fotografía» en Chile. Algunas de estas voces (como el caso de Fonseca) reparan en la falta de un lenguaje crítico y especializado que da cuenta del fenómeno fotográfico de manera autónoma. Otras llegan a plantear la inexistencia de una «historia de la fotografía» en Chile. Varios, sobre todo los fotógrafos profesionales, plantean desde muy temprano el lugar imposible de la fotografía dentro del espacio de las artes visuales. Así, por ejemplo, se lee en una nota publicada en 1983 en Punto de Vista: «En fotografía [...]no hay ni siquiera buenos comentaristas 'oficiales' y se toma en general un lenguaje prestado de la plástica. Nadie se interesa realmente en el problema que plantea la fotografía, porque aún no se la acepta como arte. Se la siente como un METETE, una AMENAZA que viene a desestabilizar códigos y estructuras» (s/p, énfasis en el original). Al mismo tiempo, mientras fotógrafos y reporteros gráficos señalan la precariedad del medio en el que se desarrolla 
la fotografía, algunos críticos van a oponer el trabajo «de denuncia» o contingencia realizado por estos individuos a las obras realizadas por «fotógrafos artistas» ${ }^{11}$.

Los distintos discursos develan asimismo el complejo estatuto de la imagen fotográfica como mecanismo de mediación: y es que al tiempo que la imagen mediática opera como aparato reproductor de la ideología oficialista -en periódicos, revistas y en la televisión- también opera en sentido contrario, es decir, criticando el carácter controlador, propagandístico, repetitivo y, por ende, anestésico de aquella imagen mediática $^{12}$. Sin embargo, para algunos, incluso aquellas imágenes que intentan destrabar el sentido terminan produciendo una "alienante visualidad previsible». Así lo va a sugerir Lihn en 1985 en una de sus reseñas, sobre las cuales volveré en el próximo apartado:

Ha llegado a ser lamentablemente fácil captar imágenes truculentas de la batalla desigual en que los oprimidos son metáforas del martirio y los opresores, emblemas del terrorismo de Estado. La reiteración de visiones semejantes propaga el terror, anestesiando, a la vez, la sensibilidad del público que puede habituarse, como al toque de queda, a la violencia institucionalizada (458).

En estos términos va adquiriendo forma, en el Chile de los ochenta, la conocida oposición entre fotografía documental (o reportaje gráfico) y fotografía artística o estética, esta última más emparentada con las artes visuales y con propuestas teóricas sobre lo fotográfico ${ }^{13}$.

Una de las consecuencias de esta oposición es que en la coyuntura de los años ochenta, y en un intento por desligar las artes visuales y el debate teórico sobre la llamada «Escena de Avanzada» de los discursos y prácticas de una izquierda más tradicional y comprometida, cuya denuncia era, por así decirlo, más frontal, cierto sector de la crítica académica ignora, o no sabe ver, por ejemplo, el significativo aporte que hacen para instaurar un lenguaje fotográfico los fotógrafos de la AFI. Fonseca es uno de los pocos que destaca la importante labor de la AFI, lo que se hace manifiesto en su ensayo de presentación y, por supuesto, en la curatoría de

11 Esta distinción sigue operando en el modo en el que la crítica se refiere hoy a la fotografía del período: «Las consideraciones sobre la fotografía chilena en el siglo xx tienen un capítulo destacado en la década de los ochenta, donde fotografía de autor y fotografía de compromiso se imbrican, articulan y coordinan una inédita renovación en los campos de la visualidad nacional» (Leiva Quijada, Multitudes en sombras 15, énfasis agregado).

12 Richard, por ejemplo, destaca el hecho de que «la fotografía relaciona al artista con la tecnología visual del entorno en medio del cual y con el cual compite la obra de arte, al ocupar las mismas técnicas de procesamiento mediático que controlan las sociedades de masas. Al insertar la obra en la red comunicacional de los mensajes de prensa, el recurso crítico-social de la fotografía patentiza la materialidad informativa de la sustancia ideológica que el arte se propone corregir en la imagen reproducida» (Márgenes 47).

13 El hecho de que Richard privilegie lo documental de la imagen fotográfica al reflexionar acerca de la polémica que se dio en el campo artístico nacional entre «lo documental (la neutralidad de la técnica en la fotografía) y lo representativo (la expresividad del gesto en la pintura)» (Márgenes 47), no contradice esta idea. Es el desplazamiento de la imagen fotográfica y su puesta en operación con otros elementos al interior de la obra lo que se destaca en la lectura de Richard, no la fotografía documental en sí. Por ejemplo, en Dittborn, es la reutilización de las fotografías de carné lo que viene a otorgarle un sentido "otro" o a resignificar la imagen fotográfica (Richard, Márgenes 47$50)$. 
Chile Vive, donde más de la mitad de los fotógrafos seleccionados son miembros de la $\mathrm{AFI}^{14}$. Así presenta a este grupo de fotógrafos en dicho ensayo:

Han concurrido [...] quienes coinciden en un pensamiento exigente sobre la fotografía como instancia de expresión, valoran la calidad y la disciplina en su ejercicio, y postulan un compromiso con la realidad social y política del país, tan crucial como inevitable. La vocación de este incipiente movimiento cultural, a la vez que agrupación gremial, se consolida en los breves años que transcurren. Participa en numerosas exposiciones individuales y colectivas dentro y fuera de los ámbitos habituales -van a parroquias, poblaciones marginales, galerías alternativas, además de ocupar el circuito que aparece en las guías culturales-. Participa también en la organización de encuentros y publicaciones en los que priman objetivos básicos como dignificar la profesión y generar calor entre colegas, frente a un medio institucional indiferente cuando no bostil ( $\mathrm{A}$ propósito»s/p, énfasis agregado).

Aquí se aprecia cómo Fonseca aprovecha el espacio de esta plataforma internacional para manifestar su descontento ante las divisiones y oposiciones generadas en el campo cultural chileno de la época.

A pesar de la relevancia y propuesta fotográfica de varios de los miembros de la AFI y de su reconocimiento en el extranjero a partir de exposiciones como Chile Vive, iniciativas curatoriales como la de Rouillé, por ejemplo, siguen "segregando" la fotografía documental realizada por estos fotógrafos. Esta, al parecer, no habría logrado constituirse, a diferencia de la así llamada fotografía artística o experimental, en un medio para reflexionar sobre lo fotográfico y sobre la especificidad de ese lenguaje. Lo anterior se percibe también en uno de los primeros recuentos críticos (sin dudas indispensable) de la fotografía del período; me refiero al texto de Claudia Donoso escrito en 1990 para un número especial de Cuadernos Hispanoamericanos sobre la cultura chilena bajo la Dictadura. En ese ensayo, Donoso comenta:

Poniéndolo en palabras de Barthes la fotografía de estos años ha trabajado bastante con el studium pero tal vez no se ha preocupado demasiado por el punctum. Esto ha producido cierta distorsión en el camino de liberación del ojo propio, en favor de una trampa retórica: demasiadas imágenes de pacos apaleando civiles, mucho carro lanzaaguas desaforado, exceso de niños y madres sufrientes en ollas comunes, pérdida de intensidad de tanto puño levantado desafiando al fascismo (31-2).

Debo advertir que mi ánimo no es el de reivindicar la labor fotográfica de la AFI en el período de la Dictadura -académicos como Leiva Quijada y otros ya se han abocado a esta tarea- sino que, como planteo en la Introducción, reevaluar las distinciones y oposiciones entre los modos de ser y hacer de la fotografía, así como examinar la discrepancia manifiesta en los espacios discursivos de la fotografía en el Chile de esta época ${ }^{15}$.

14 Como plantea Leiva Quijada, la AFI «se constituye en una refundación de la visualidad chilena» (Multitudes en sombras 18).

15 Esta discrepancia entre los modos de hacer y ser de la fotografía, por supuesto, no se circunscribe al campo chileno de este período, sino que es de larga data. Desde su invención en el siglo XIX, la 


\section{DEL REPORTAJE GRÁFICO AL TRABAJO FOTOGRÁFICO: LAS RESEÑAS DE ENRIQUE LIHN}

Para finalizar, me detendré brevemente en algunas reseñas y notas escritas por Enrique Lihn durante los años ochenta (recientemente recopiladas en Textos sobre arte), ya que en ellas se delinea claramente la oposición que formulo en el apartado anterior. En estas reseñas y notas, Lihn reflexiona sobre distintos aspectos, temáticas, autores y eventos relacionados a la fotografía. Al ser considerados en conjunto, es posible apreciar en estos textos la elaboración de una especie de teoría sobre el lenguaje fotográfico, coherente con las ideas de Lihn respecto del arte y el fenómeno estético. De estas reseñas se desprende, por ejemplo, la idea de que la fotografía documental «informa», lo cual la posiciona del lado de la historia y del archivo. Según Lihn, reporteros gráficos y fotógrafos llevarían a cabo la tarea de «documentar» e «informar» «de espaldas a una estética de las artes visuales», tal como lo plantea en una breve reseña aparecida en Cauce en 1986 sobre Felipe Landea -cuyas obra, evidentemente, no sería parte de esta tendencia-. El siguiente pasaje ilustra esta cuestión:

La mayoría de nuestros fotógrafos, agrupados en la Asociación Gremial de Fotógrafos Independientes de Chile (AFI), son o fueron reporteros gráficos. La regla [...] desaconseja la presencia del operador mismo como objetivo y estimula, a la inversa, la soberanía de la contingencia, el encuentro fortuito del ojo de la cámara con las particularidades inquietantes de la realidad individual o social, y deslinda así el trabajo del fotógrafo de cualesquiera estéticas que lo asocien, en tanto fotografía de arte, a la belleza de lo imaginario [...] De espaldas a una estética de las artes visuales, nuestros fotógrafos preferirán la proximidad a la antropología o la sociología. Hacen historia a su manera, levantando el catastro de una catástrofe (483, énfasis agregado).

En el argumento de Lihn se deja traslucir la idea de que existirían dos formas de representación que se perciben como opuestos o excluyentes: el modo documental (ligado a una dimensión testimonial, informacional o de denuncia) y el modo experimental (ligado a una dimensión estética o artística). En este tipo de formulaciones, la fotografía de denuncia o informativa va a depender casi por completo del contexto en la cual es presentada y observada. Esta idea aparece también expresada en una reseña de 1985 dedicada al libro Cada día, que reúne las fotografías de Álvaro Hoppe:

El reportero gráfico documenta situaciones o retrata personajes de los que el periodista habla o a los que hace hablar, con imágenes ocasionales a las cuales les falta, pues,

fotografía ha estado siempre acompañada de una serie de discursos que han debatido su valor, ya sea artístico, científico, histórico o documental. Dubois distingue tres grandes tendencias o discursos: en el siglo XIX habría predominado, según el crítico, el discurso de la mímesis y la visión de la fotografía como «espejo de lo real» (31). En el siglo xx , según Dubois, habrían prevalecido dos discursos: el de la deconstrucción, el cual percibiría «la fotografía como transformación de lo real» y como una manifestación culturalmente codificada; y el discurso del índex y la referencia, el cual pensaría la «fotografía como huella de un real» (el ejemplo paradigmático sería La cámara lúcida de Roland Barthes) y cuyo precedente serían las ideas de Walter Benjamin. La teorización de Krauss también se insertaría en esta tercera corriente. 
el texto, la leyenda, o el diálogo. No son suficientes en sí mismas. Un buen reportero gráfico puede hacer asi un trabajo documentalmente eficiente, pero fotográficamente irrelevante. Al hablar por sí mismo, el reportaje gráfico traspasa la frontera y se convierte en un trabajo fotográfico. Es decir, es un mensaje visual afectado [...] por la lengua, desde la visualidad misma (455, el énfasis es mío).

Lihn, al mismo tiempo en que insiste en el valor informacional de la fotografía documental y del reportaje gráfico, sugiere que la obra fotográfica de Hoppe se distinguiría de la fotografía del «reportaje gráfico» en que iría más allá de la dimensión documental o informativa. Lihn sugiere de todos modos en que para "'leer' adecuadamente Cada día, la colección fotográfica de Álvaro Hoppe. [...] es mejor que el receptor del mensaje conozca la historia reciente de Chile a partir de las protestas» $(456)^{16}$.

Como es posible apreciar, las ideas de Lihn en torno a la fotografía documental coinciden con las de otros discursos de los años ochenta. La posibilidad de una reflexión teórica sobre lo fotográfico y la conformación de un lenguaje visual "otro" se produciría en el espacio de las artes visuales, en la obra de aquellos que Rouillé denomina fotógrafos-artistas, o en la obra de aquellos fotógrafos que logran «trascender» la dimensión informativa y denotativa del reportaje gráfico. La diferencia cualitativa entre reporteros y fotógrafos que se aprecia en la última cita de Lihn no rompe con esta lógica: el reportaje gráfico es de una mayor complejidad que la foto informativa del reportero precisamente porque «nos comunica algo» desde la visualidad misma. En las fotografías documentales, parece decirnos Lihn, no habría nada que descifrar, ya sea porque la información está contenida en la imagen, o porque la imagen viene a ilustrar lo que dice un texto. Al parecer, a los fotógrafos o reporteros no les quedaría más que denunciar o informar acerca de un estado de la situación por medio de sus fotografías.

De estos discursos se desprende la idea de que las fotografías documentales no podrían no decir, ni muchos menos sugerir, una diferencia entre lo visto y lo dicho. El propósito de la fotografía documental sería atestiguar, quedando restringida al ámbito de lo útil. Si bien no pretendo desestimar el valor de documento de la imagen fotográfica -esta es, sin lugar a dudas, un arma efectiva de denuncia-, sí me parece importante insistir en la opacidad y el potencial movilizador de la fotografía, sea artística o documental. Como sugerí en la introducción, el signo fotográfico es un signo complejo: índice, icono y símbolo. Esta complejidad la vuelve un signo indecidible (al decir de Durand), esto es, un signo en tensión constante. Entonces, la tensión del fenómeno fotográfico se hace manifiesta en la posibilidad que tiene

16 Gonzalo Leiva Quijada también destaca el hecho de que la fotografías de Hoppe trascienden, de cierta manera, la contingencia: «Álvaro Hoppe, logra compensar la precariedad anímica producto de empujones, bombas lacrimógenas y golpeaduras, con una lucidez visual que conserva una auténtica, dinámica y convulsa belleza» (Álvaro Hoppe 81); «La demanda contemplativa en los trabajos de Hoppe indica un momento acucioso de visualización, pues si bien en muchas de sus imágenes el mensaje es directo, sus atractivos componentes y las informaciones sostenidas pueden abrir nuevos sentidos e interpretaciones» (Álvaro Hoppe 140). 
cada fotografía, de decir o no decir, o de decir diferente. Pero la recurrente división en dos sistemas de legibilidad de la imagen - un modo documental «transparente» y un modo artístico «opaco»- parece impedirnos apreciar la indecidibilidad de la imagen fotográfica en la fotografía documental.

\title{
III. LA TENSIÓN DE LO FOTOGRÁFICO
}

\author{
Articular históricamente el pasado no significa conocerlo \\ 'como verdaderamente ha sido'. Significa apoderarse de un recuerdo \\ tal como este relampaguea en un instante de peligro. \\ Benjamin, La dialéctica en suspenso.
}

Enrique Lihn privilegia en sus reseñas la fotografía artística o experimental (la fotografía de Paz Errázuriz, Álvaro Hoppe, Felipe Landea o Inés Paulino) por sobre aquella que levanta el «catastro de la catástrofe»; André Rouillé deja la fotografía documental fuera del espacio del Museo porque ve en ella un medio de inscripción (y no de representación) de la contingencia. Ambas perspectivas coinciden en que piensan, y exhiben, la imagen fotográfica documental como imagen transparente o, al decir de Jacques Rancière, como "imagen desnuda». La imagen desnuda, sugiere Rancière, "es la imagen que no constituye arte, porque lo que nos muestra excluye el prestigio de la no semblanza y la retórica de la exégesis» $(22)^{17}$. El problema de esta hipótesis, tal como apunta el filósofo francés, es que la imagen fotográfica nunca se presenta completamente desnuda: lo dicho revela lo no dicho, lo que aparece exhibe la traza de aquello que se esconde ${ }^{18}$. Rancière sugiere por este motivo que la fotografía devino arte "only by exploiting a double poetics of the image, by making its images, simultaneously or separately, two things: the legible testimony of a history written on faces or objects and pure blocs of visibility, impervious to any narrativization, any intersection of meaning» $(11)^{19}$. Si bien concuerdo en que existe una tensión permanente entre lo visible y lo no visible, lo dicho y lo no dicho, me interesa reclamar esta tensión como un atributo inherente del fenómeno fotográfico, y no solo como una cualidad de la imagen artística (como sugiere Rancière). Así visto, aquello que Rouillé denominara

«[is] the image that does not constitute art, because what it shows excludes the prestige of dissemblance and the rhetoric of exegesis"

18 Susan Sontag decía que «una fotografía es a la vez una pseudopresencia y un signo de ausencia» (25). Pero aquello que está ausente de la imagen fotográfica no tiene que ver solo con el signo de muerte que acarrea toda fotografía-tropo, demás está decirlo, comentado en extenso por fotógrafos, críticos, especialistas y aficionados-sino con aquello que está ausente en y del mismo campo de lo visible: tanto aquello que no vemos dentro del encuadre (zonas borrosas, oscuras), como aquello que queda, por así decirlo, fuera del marco. (Ver Didi-Huberman, capítulos 1 y 2 ).

19 «[...] al explotar la doble poética de la imagen, al hacer de sus imágenes dos cosas simultáneamente: por un lado, el testimonio legible de una historia escrita en caras u objetos y por otro lado, bloques puros de visibilidad, impermeables a cualquier narrativización, cualquier intersección de sentido" (Rancière 11; la traducción es mía). Según Rancière, es en esta tensión inherente de la imagen fotográfica en donde aparece la fotografía como operación artística (Rancière 6-7). 
«los límites de la fotografía» o «posfotografía» puede ser pensado y abordado a partir de la noción de lo fotográfico y desde dentro del campo de la fotografía.

Las fotografías «de archivo», «documentales» o «artísticas» son todas ellas sobrevivientes silenciosas que pueden, sin lugar a dudas, ayudarnos a abrir el presente, tal como sugiere Didi-Huberman en el epígrafe citado al comienzo de este ensayo. Las fotografías de Kena Lorenzini, Álvaro Hoppe, Jorge Ianiszewski o Marcelo Montecino, por ejemplo, establecen una relación entre temporalidad, instante y pérdida que tiene directa relación con el modo de inscripción propio de la fotografía. Asimismo, estas fotografías proponen relaciones entre sujetos, tiempos y espacios, entre signos, modos de ser y de hacer que se actualizan y modifican cada vez que una persona las observa ${ }^{20}$. Al poner el énfasis en los discursos $-\mathrm{y}$ no ya en el valor documental o artístico de las fotografías-, y al atender a aquello que en estas imágenes fotográficas aparece en tensión o no resuelto, es posible reconfigurar y repensar el campo fotográfico; un campo que tal y como fue formulado en los espacios discursivos de la fotografía desde fines de los setenta, se encuentra dividido y limitado a ciertos modos de hacer y de ser de lo fotográfico. En las fotografías documentales, sin lugar a dudas, hay huellas de significativos eventos del pasado (bombardeos, protestas o vigilias), pero no hay que olvidar, y este reclamo es de inspiración benjaminiana, que los sujetos que aparecen en estas fotografías son poseedores «[...] de un secreto que nunca conoceremos, un secreto velado por la misma imagen que los trae a nosotros» (Rancière 15) ${ }^{21}$. Si atendemos a este reclamo, este período emerge como un espacio / tiempo de una extraordinaria riqueza para indagar en la doble poética de la imagen, reformular el campo fotográfico mediante un delineamiento de los espacios discursivos de la fotografía y así arrojar nuevas luces sobre nuestra memoria fotográfica.

\section{REFERENCIAS}

«Ausencia de la crítica: un comentario». Punto de Vista 3 (1983). s/p. Medio impreso. «Editorial». CAL 4 (1979). 2. Medio impreso.

Alegría Licuime, Luis. "Fragmento fotográfico. Arte, narración y memoria. Chile 19801990. Kena Lorenzini». Kena Lorenzini. Fragmento fotográfico. Arte, narración y memoria. Chile 1980-1990. Santiago: Ocho Libros, 2006. s/p. Medio impreso.

Barthes, Roland. Camera Lucida. Reflections on Photography. Trad. Richard Howard. New York: Hill and Wang, 1982. Medio impreso.

Benjamin, Walter. «Little History of Photography». Selected Writings. Volume 2, Part 2, 1931-1934. Eds. Michael W. Jennings et al. Trad. Rodney Livingstone et al. Cambridge: Belknap Press, 2005. 507-30. Medio impreso.

20 En las fotografías de Lorenzini, tal como plantea Luis Alegría, «el lente no se guía por ninguna ética o moral, pues al descubrir el gesto rígido de ciertas autoridades o el rostro de personajes anónimos, la imagen devela algo más que la simple realidad y la crudeza de su existencia» (s/p).

21 "of a secret we shall never know, a secret veiled by the very image that delivers them to us" (Rancière 15, la traducción es mía). 
---. La dialéctica en suspenso. Fragmentos sobre historia. Trad. Luis Oyarzún. Santiago: LOM Ediciones, 2009. Medio impreso.

Concha, José Pablo. La desmaterialización fotográfica. Santiago: Metales Pesados, 2012. Medio impreso.

Didi-Huberman, Georges. Images Malgré Tout. París: Les Éditions de Minuit, 2003. Medio impreso.

Donoso, Claudia. «16 años de fotografía en Chile. Memoria de un descontexto». Revista de Crítica Cultural 2 (1990). 28-32. Medio impreso.

Dubois, Philippe. El acto fotográfico. Trad. Víctor Goldstein. Buenos Aires: La Marca, 2008. Medio impreso.

Durand, Régis. El tiempo de la imagen. Ensayo sobre las condiciones de una historia de las formas fotográficas. Trad. Mónica Gómez Prado. Salamanca: Ediciones Universidad de Salamanca, 1998. Medio impreso.

Agrupación Cultural Puliwen-Antu. Primer anuario fotográfico chileno. Santiago: Agrupación cultural Puliwen-Antu, 1981. Medio impreso.

Ferrer, Rita. Yo, fotografía. Santiago: Ediciones La Hetera, 2002. Medio impreso.

Fonseca Velasco, Mario. Fotografía. 1986-1995. Santiago: Museo Nacional de Bellas Artes, 1996. Medio impreso.

---. «A propósito de la fotografía en Chile». Blog de Mario Fonseca Velasco. Fecha de ingreso: 23 de febrero de 2012. <http://bit.ly/c5PGVU>. Sitio web.

---. «Habeas Corpus. Mario Fonseca». Revista Escáner (2011). Fecha de ingreso: 3 de febrero de 2012. <http://bit.ly/ZKAPD4>. Sitio web.

Jösch, Andrea. «Curatoría AFA01». AFA01. Santiago: Galería AFA, 2006. 32-9. Medio impreso.

Kay, Ronald. Del espacio de acá. Señales para una mirada americana. Santiago: Metales Pesados, 2005. Medio impreso.

Krauss, Rosalind. Le Photographique. Pour un théorie des Écarts. Trad. Marc Bloch y Jean Kempf. París: Macula, 1990. Medio impreso.

Leiva Quijada, Gonzalo. Álvaro Hoppe: El ojo en la historia. Santiago: Fondart, 2003. Medio impreso.

---. Multitudes en sombras. AFI, Asociación de Fotógrafos Independientes. Santiago: Ocho Libros, 2008. Medio impreso.

Lihn, Enrique. Textos sobre arte. Eds. Adriana Valdés y Ana María Risco. Santiago: Universidad Diego Portales, 2008. Medio impreso.

Mellado, Justo Pastor. «La novela chilena de Mario Fonseca». Fotografía. 1986-1995. Mario Fonseca Velasco. Santiago: Museo Nacional de Bellas Artes, 1996. s/p. Medio impreso.

Rancière, Jacques. The Future of the Image. Trad. Gregory Elliott. Nueva York: Verso, 2007. Medio impreso.

Richard, Nelly. «Bordes, límites, fronteras». Los límites de la fotografía. Ed. André Rouillé.

París: AFAA, 1996. 6-7. Medio impreso. 
---. Márgenes e instituciones. Arte en Chile desde 1973. Santiago: Metales Pesados, 2007. Medio impreso.

Rouillé, André. Los límites de la fotografía. París: AFAA, 1996. Medio impreso.

Sontag, Susan. Sobre la fotografía. Trad. Carlos Gardini. Barcelona: Alfaguara, 2006. Medio impreso. 